\title{
'BRS Mari': nova cultivar de pimenta dedo-de-moça para processamento
}

\author{
Sabrina Isabel C de Carvalho; Cláudia SC Ribeiro; Gilmar Paulo Henz; Francisco José B Reifschneider \\ Embrapa Hortaliças, C. Postal 218, 70359-970 Brasília-DF, sabrina@cnph.embrapa.br
}

\begin{abstract}
RESUMO
'BRS Mari’ é uma nova cultivar de pimenta dedo-de-moça desenvolvida para uso múltiplo, como produto in natura, processada na forma de molho líquido ou desidratada em flocos, moída junto com as sementes, para a produção de pimenta tipo 'calabresa'. A cv. 'BRS Mari' foi desenvolvida a partir da população 'CNPH 0039' por meio de seis ciclos de seleção massal com autofecundação controlada. A nova cultivar apresenta plantas de polinização aberta com hábito de crescimento intermediário, com aproximadamente $90 \mathrm{~cm}$ de altura e 1,25 m de largura, com resistência múltipla a doenças, com destaque para o virus Pepper Yellow Mosaic Virus (PepYMV) e nematóide das galhas (Meloidogyne javanica), resistência mediana ao oídio (Oidium sicula), mancha bacteriana (Xanthomonas spp.) e antracnose (Colletotrichum spp.). A colheita dos frutos tem início cerca de 70 dias após o transplante. Nas condições da região Centro-Oeste, 'BRS Mari' apresentou boa uniformidade de planta, ótima qualidade de fruto e grande potencial produtivo, alcançando $35 \mathrm{tha}^{-1} \mathrm{em}$ seis meses, quando cultivada no espaçamento de $1 \mathrm{~m}$ entre plantas e 1,5 $\mathrm{m}$ entre linhas. Os frutos são alongados e pendentes, típicos do tipo dedo-de-moça, com passagem de coloração verde claro, amarelo com antocianina e laranja quando imaturos e vermelho intenso quando maduros, com aproximadamente $6,0 \mathrm{~cm}$ de comprimento, $1,4 \mathrm{~cm}$ de largura e cerca de $1,7 \mathrm{~mm}$ de espessura da parede. A principal característica da 'BRS Mari' é o elevado teor de capsaicina, aproximadamente $90.000 \mathrm{SHU}$ (Unidades de Calor Scoville), mais elevado quando comparada com outras cultivares do mesmo grupo.
\end{abstract}

Palavras-chave: Capsicum baccatum var. pendulum, resistência, processamento, capsaicina.

\section{ABSTRACT \\ 'BRS Mari': new hot pepper cultivar for processing}

'BRS Mari' is a new hot pepper cultivar suitable for processing as sauce or dehydrated flakes, ordinarily known in Brazil as 'calabresa' type, as well as for fresh market. Hot pepper cv. 'BRS Mari' was obtained from population 'CNPH 0039', through six cycles of mass selection with controlled selfing of selected plants. The new multipledisease resistant, open pollinated cultivar has an intermediate habit growth, reaching $90 \mathrm{~cm}$ in height and $1.25 \mathrm{~m}$ in width; it is highly resistant to Pepper Yellow Mosaic Virus (PepYMV) and to root-knot nematode (Meloidogyne javanica), and it is moderately resistant to mildew (Oidium sicula), bacterial spot (Xanthomonas spp.) and anthracnose (Colletotrichum spp.). Fruit harvest begins 70 days after transplanting. In Central Brazil, cv. 'BRS Mari' showed high plant uniformity, excellent fruit quality and high potential yield, reaching $35 \mathrm{t} \mathrm{ha}^{-1}$ in six months. Fruits are pendant and elongated, typical of 'dedo-de-moça' type, $6.0 \mathrm{~cm}$ in length, $1.4 \mathrm{~cm}$ in width and $1.7 \mathrm{~mm}$ thick. Fruit color changes from light green to yellow with anthocyanin and orange when immature and to intense red when fully ripe. The most important trait of 'BRS Mari' is the high capsaicin content, approximately 90,000 Scoville Heat Units (SHU), which is higher than other Brazilian cultivars of the same group.

Keywords: Capsicum baccatum var. pendulum, resistance, processing, capsaicin.

\section{(Recebido para publicação em 10 de fevereiro de 2009; aceito em 6 de novembro de 2009)}

(Received in February 10, 2009; accepted in November 6, 2009)

\begin{abstract}
$\mathrm{A}^{\mathrm{p}}$ pimenta dedo-de-moça (Capsicum baccatum var. pendulum) conhecida como pimenta-vermelha, calabresa ou chifre-de-veado, é uma das mais consumidas no Brasil, principalmente nos estados do Rio Grande do Sul, São Paulo e Goiás. O seu cultivo é realizado por pequenos, médios e grandes produtores e se ajusta perfeitamente aos modelos de agricultura familiar e de integração pequeno agricultoragroindústrias.
\end{abstract}

Agricultores de base familiar no município de Turuçu, Rio Grande do Sul, conhecido como a "Capital
Nacional da Pimenta" cultivam pimenta dedo-de-moça há mais de 50 anos, utilizando sementes de populações locais obtidas em suas próprias lavouras (Madail et al., 2005).

O sistema de produção nesse município, levantado em 2002, era conduzido de maneira simples, com baixo nível tecnológico.

Os custos variáveis de produção também eram baixos, tendo como principal item a utilização de mão-deobra, estimado em aproximadamente $60,8 \%$ do total (Vilela et al., 2008). Nos últimos anos tem sido observado um aumento significativo de perdas durante o cultivo causado pela antracnose (complexo de espécies de fungos do gênero Colletotrichum) afetando sobremaneira os frutos, inviabilizando a produção.

Os danos causados por essa doença têm causado uma redução no número de produtores e na área cultivada no município, que passou de 120 ha para 70 ha, na safra 2004-2005 (Barbieri, 2006) e continua decrescendo.

Os pequenos produtores de base familiar de pimenta geralmente produzem sementes para uso próprio 
de populações locais, direito que lhes é assegurado pela Lei de Sementes $n^{\circ}$ 10.711/03.

Apesar do crescente interesse no cultivo de pimentas no país, poucas empresas que produzem e comercializam semente têm demonstrado interesse no desenvolvimento de novas cultivares. Ultimamente, com a possibilidade de proteção das cultivares de pimenta, esse cenário vem mudando, tanto que já estão em processo de proteção cultivares de pimentas para os vários segmentos da produção (Freitas et al., 2008).

As plantas de pimenta tipo dedo-demoça são arbustivas, com cerca de $1 \mathrm{~m}$ de altura. Os frutos são alongados, de coloração vermelha quando maduros, medem cerca de 1,0 a $1,5 \mathrm{~cm}$ de diâmetro, de 8 a $10 \mathrm{~cm}$ de comprimento e pungência que varia de suave a mediana (Carvalho et al., 2006; Moreira et al., 2006). Dependendo da região e do uso, as pimentas do tipo "dedo-de-moça" podem ter diferentes nomes, como "Chifre de Veado", quando os frutos são maiores, e "Vermelha" ou "Calabresa" quando usadas desidratadas na forma de flocos (Carvalho et al., 2006; Moreira et al., 2006).

O presente trabalho teve como objetivo descrever as características fenotípica e genotípica de uma nova cultivar de pimenta tipo 'dedo-demoça' obtida pela equipe do Programa de Melhoramento de Capsicum da Embrapa Hortaliças.

\section{ORIGEM}

A cultivar de pimenta dedo-de-moça 'BRS Mari' (Figura 1) foi desenvolvida a partir da população CNPH 0039, introduzida na coleção de germoplasma de Capsicum da Embrapa Hortaliças em coleta realizada em 1980 em BrasíliaDF, por F. Reifschneider. Foram feitos seis ciclos de seleção massal com autofecundação controlada, sendo feito um bulk das sementes originárias das plantas selecionadas.

\section{DESCRIÇÃO}

A cultivar de pimenta dedo-demoça 'BRS Mari' apresenta plantas

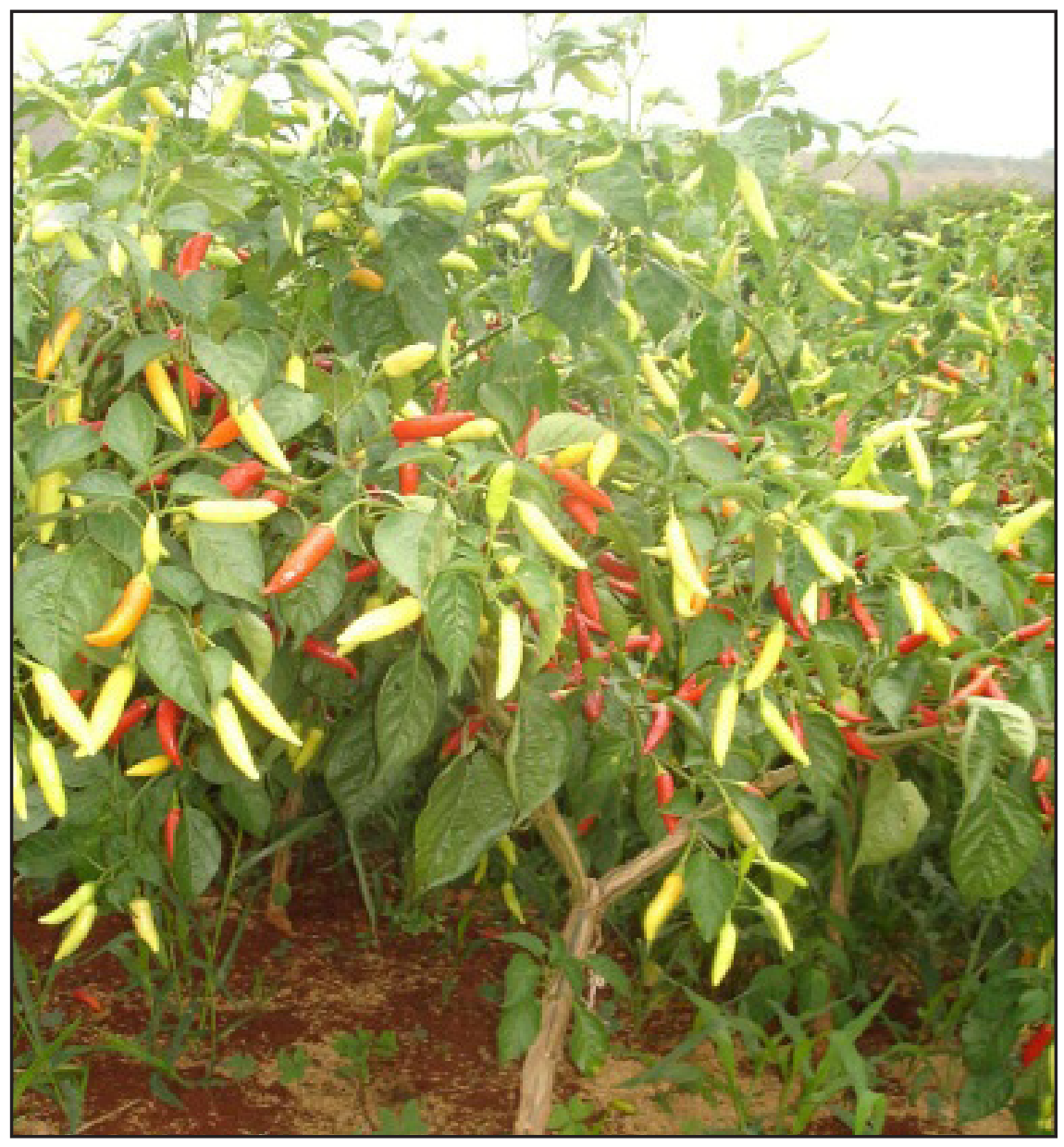

Figura 1. Planta da pimenta tipo dedo-de-moça da cv. 'BRS Mari', arbustiva e com aproximadamente $1 \mathrm{~m}$ de altura (plant of hot-pepper cv. 'BRS Mari', with intermediate habit growth, around $1 \mathrm{~m}$ height). Brasília, Embrapa Hortaliças, 2009.

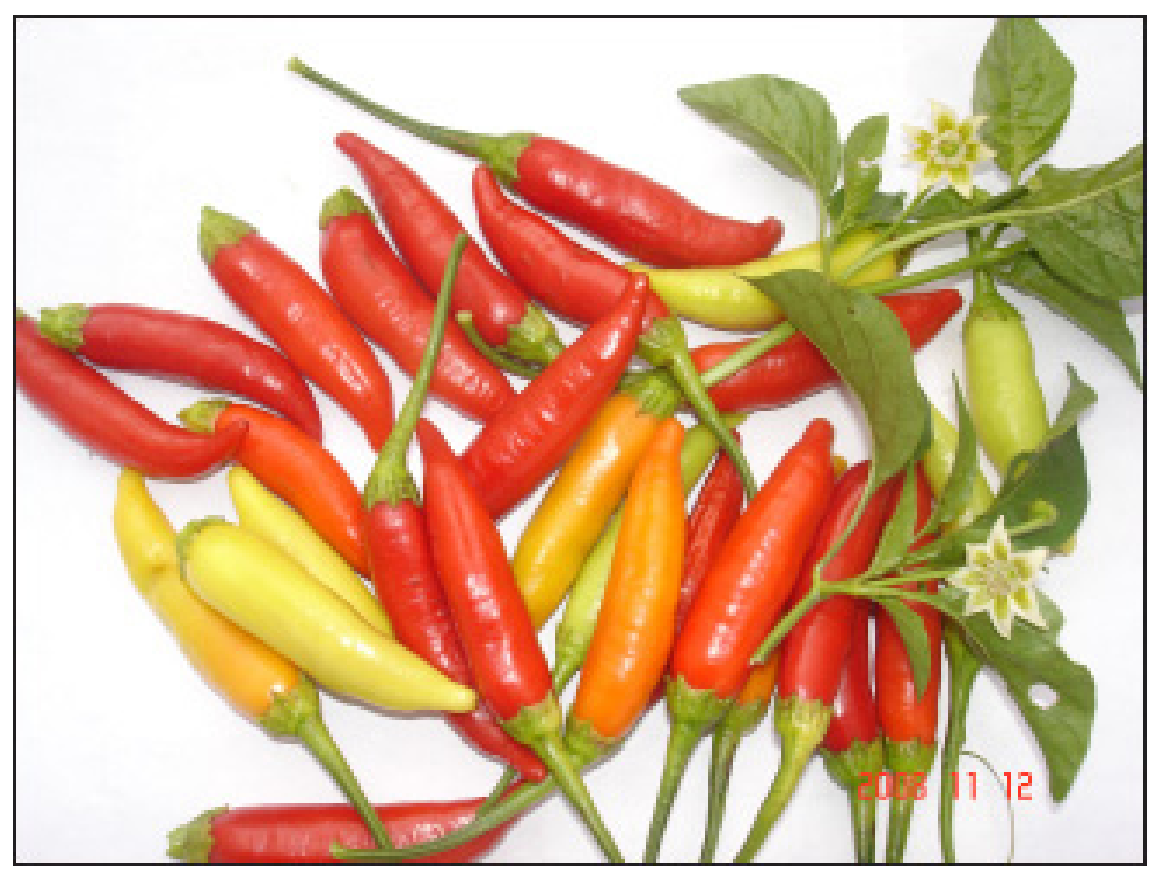

Figura 2. Frutos de pimenta tipo dedo-de-moça da cv. 'BRS Mari', com coloração variando de verde-claro a vermelho intenso (hot pepper fruits, cv. 'BRS-Mari', whose color varies from light green to deep red). Brasília, Embrapa Hortaliças, 2009. 
de polinização aberta com hábito de crescimento intermediário, com aproximadamente $90 \mathrm{~cm}$ de altura e 1,25 $\mathrm{m}$ de largura (Figura 1). 'BRS Mari' apresenta resistência múltipla a doenças, com destaque para o potyvírus Pepper Yellow Mosaic Virus (PepYMV), resistência mediana ao oídio (Oidium sicula) e à mancha bacteriana (Xanthomonas spp.).

A principal característica da 'BRS Mari' é o elevado teor de capsaicina em seus frutos (alcalóide que confere a pungência das pimentas) se comparadas com outras cultivares do mesmo grupo. $\mathrm{O}$ teor de capsaicina pode oscilar em função de vários fatores, entre os quais o ambiente de cultivo (especialmente temperatura), posição do fruto na planta e tratos culturais utilizados durante o período de cultivo, como adubação, irrigação, incidência de pragas e doenças, entre outros.

A colheita dos frutos tem início cerca de 70 dias após o transplante das mudas. Nas condições da região CentroOeste, a cultivar 'BRS Mari' apresentou boa uniformidade de planta, ótima qualidade de fruto e grande potencial produtivo, alcançando cerca de $35 \mathrm{t}$ $\mathrm{ha}^{-1}$ em seis meses, quando cultivada no espaçamento de $1 \mathrm{~m}$ entre plantas e 1,5 $\mathrm{m}$ entre linhas.

Os frutos são alongados e pendentes, típicos do tipo dedo-de-moça, com passagem de coloração verde claro, amarelo com antocianina e laranja quando imaturos, ficando vermelho intenso quando maduros (Figura 2). Medem aproximadamente $6,0 \mathrm{~cm}$ de comprimento, 1,4 cm de largura e 1,7 $\mathrm{mm}$ de espessura da parede. Os frutos são bastante pungentes com teor de capsaicina em torno de 90.000 SHU (Unidades de Calor Scoville).

\section{USOS}

Os frutos maduros da cultivar 'BRS Mari' podem ser destinados tanto ao mercado in natura como para o processamento na forma de molhos líquidos e desidratados em flocos com as sementes ("pimenta calabresa").

No processamento da pimenta calabresa realizado em Turuçu-RS, os frutos da pimenta dedo-de-moça são colhidos vermelhos e secos ao sol sobre lonas. Depois de secos e desidratados são moídos inteiros, inclusive com as sementes. A coloração do fruto vermelha intensa verificada na 'BRS Mari' é uma característica importante de qualidade para a matéria-prima processada, pois confere ao produto maior padrão de qualidade no processo de desidratação (Ribeiro et al., 2008). A cultivar 'BRS Mari' possui grande potencial para ser utilizada na produção de pimenta calabresa, pois seu alto conteúdo de capsaicina é altamente desejável para a indústria frigorífica para produção de embutidos e empresas que produzem temperos. Pelas suas características, a cultivar 'BRS Mari' pode ser recomendada para a agricultura familiar como alternativa de diversificação da produção, representando uma importante fonte de geração de emprego e renda para os agricultores, possibilitando a agregação de valor na forma processada, detendo amplas oportunidades de mercado, tanto na forma in natura como processada.

\section{EQUIPE}

A cultivar de pimenta dedo-de-moça 'BRS Mari' foi desenvolvida pela equipe de pesquisadores, analistas e técnicos agrícolas participantes do programa de melhoramento de espécies do gênero Capsicum da Embrapa (Hortaliças, Recursos Genéticos e Biotecnologia e Agroindústria de Alimentos) nas áreas de melhoramento (Cláudia Silva da Costa Ribeiro, Francisco José Becker Reifschneider, Leonardo da Silva Boiteux, Geovani Bernardo Amaro), cruzamentos e multiplicação do material (Athayde Lemes Garcia e equipe de campo), fitopatologia (Carlos Alberto Lopes, Alice Maria Quezado Duval, Antônio Carlos de Ávila, Ailton Reis, Gilmar Paulo Henz), caracterização morfológica e molecular (Sabrina Isabel Costa de Carvalho, Luciano de Bem Bianchetti, Gláucia Salles Cortopassi Buso), avaliação do teor de capsaicina (Daíse Lopes Lutz), produção de sementes (Raquel Alves de Freitas e Warley Marcos Nascimento) e validação e extensão rural (José Lindorico de Mendonça).

\section{DISPONIBILIDADE DE SEMENTES}

A Embrapa Transferência de Tecnologia estará disponibilizando sementes para empresas produtoras de sementes interessadas na produção de 'BRS Mari'.

\section{REFERÊNCIAS}

BARBIERI RL. 2006. Pesquisa com Capsicum na Embrapa Clima Temperado. In: ENCONTRO NACIONAL DO AGRONEGÓCIO PIMENTAS (Capsicum spp.), 2.; MOSTRA NACIONAL DE PIMENTAS E PRODUTOS DERIVADOS, 2., 2006. Brasília, Anais... Brasília: Embrapa Hortaliças, 3p. 1 CDRom.

CARVALHO SIC; BIANCHETTI LB; RIBEIRO CSC; LOPES CA. 2006. Pimentas do Gênero Capsicum no Brasil. Brasília: Embrapa Hortaliças, 27p. (Embrapa Hortaliças. Documentos, 94).

FREITASRA; NASCIMENTOWM; CARVALHO SIC. 2008. Produção de sementes. In: RIBEIRO CSC; LOPES CA; CARVALHO SIC; HENZ GP; REIFSCHNEIDER (Org.). Pimentas Capsicum. 1 ed. Brasília: Embrapa Hortaliças, v. 1, p. 173-187.

MADAIL JCM; SCHNEID LF; SIMA LF; WENDT AN. 2005. Economia da produçao de pimenta vermelha no municipio de Turuçu$R S$. Pelotas: Embrapa Clima Temperado. 27p. (Embrapa Clima Temperado. Boletim de Pesquisa e Desenvolvimento, 19).

MOREIRA GR; CALIMAN FRB; SILVA DJH; RIBEIRO CSC. 2006. Espécies e variedades de pimenta. Informe Agrocuário 27: 16-29.

RIBEIRO CSC; HENZ GP. 2008. Processamento. In: RIBEIRO CSC; LOPES CA; CARVALHO SIC; HENZ GP; REIFSCHNEIDER FJB (Org.). Pimentas Capsicum. Brasilia: Embrapa Hortaliças, 2008, v.1, p. 157-171.

RIBEIRO CSC; REIFSCHNEIDER FJB. 2008. Genética e melhoramento. In: RIBEIRO CSC; LOPES CA; CARVALHO SIC; HENZ GP; REIFSCHNEIDER FJB (Org.). Pimentas Capsicum. Brasilia: Embrapa Hortaliças, 2008. p. 55-69.

VILELA NJ; RIBEIRO CSC; MADAIL JCM. 2008. Eficiência técnico-econômico de quatro sistemas de produção de pimentas Capsicum. Brasília: Embrapa Hortaliças, 7p. (Embrapa Hortaliças. Comunicado Técnico, 56). 